\title{
R-CDOP Regimen
}

National Cancer Institute

\section{Source}

National Cancer Institute. R-CDOP Regimen. NCI Thesaurus. Code C154215.

A chemoimmunotherapy consisting of rituximab, cyclophosphamide, liposomal

doxorubicin, vincristine and prednisone (R-CDOP) that can be used in the treatment of some forms of non-Hodgkin lymphoma (NHL). 